\title{
SEVERAL ASPECTS OF DESCRIPTIVE EPIDEMIOLOGY OF HEMATOLOGICAL MALIGNANCIES IN ADULT POPULATION OF UKRAINE, BELARUS AND RUSSIAN FEDERATION AFTER CHORNOBYL ACCIDENT
}

\author{
L.N. Guslitser, M.P. Zavelevich*, S.V. Koval, D.F. Gluzman \\ R.E. Kavetsky Institute of Experimental Pathology, Oncology and Radiobiology, NASof Ukraine, Kyiv 03022, Ukraine
}

Chornobyl impact on the health of adult population in Ukraine, Belarus and Russian Federation was a subject of several studies. However, the studies of the effects of Chornobyl on leukemia in adult populations in post-Soviet countries are scarce and the results are contradictory up to present. The results of the epidemiological studies of the oncohematological consequences of Chornobyl accident are briefly reviewed with particular focus on pre-Chornobyl and post-Chornobyl trends in leukemia incidence in Ukraine, Belarus and Russian Federation as well as in small territories of these countries with various levels of radionuclide contamination. This article is a part of a Special Issue entitled "The Chornobyl Nuclear Accident: Thirty Years After".

Key Words: Chornobyl, radiation, leukemia, adult population, epidemiology,

Since the first publications of the study of A-bomb survivors, excess leukemia has been considered to be the earliest indicator of the health risk associated with ionizing radiation. The relative risk for leukemia from radiation was shown to be one of the highest in comparison to other cancers [1]. The effects of irradiation due to Chornobyl in the cohorts of cleanup workers have been a subject of several studies [2]. The statistically significant radiation risks of leukemia in cleanup workers for 1986-1997 follow-up period have been demonstrated [3]. However, the data on hematological malignancies in adult population of Ukraine, Russian Federation and Belarus exposed to low dose radiation due to Chornobyl catastrophe are scarce and the results are contradictory up to present. Prior to surveying the findings of the descriptive epidemiological studies of leukemia incidence in contaminated regions of Ukraine, Russian Federation and Belarus that suffered utmost from Chornobyl radiation, it would be appropriate to compare the general temporal trends in the incidence of hematological malignancies in pre-accident period (up to 1986), early and late post-accident periods (defined differently in different studies) in these countries.

Although the National Cancer Registry of Ukraine was set up in 1989 and it was not until 2002 when the activity of the Registry covered all the territory of Ukraine, several earlier descriptive studies based on the official statistical reports of the Health Ministry of Ukraine were available to provide the general patterns of overall incidence of hemoblastoses in Ukraine. The malignant tumors of hematopoietic and lymphoid tissues as the separate sections under the entry "malignant neoplasms" started to be registered and reported to health management officials in ex-USSR since mid-60s. Until 1989, only the hemoblastoses

Submitted: November 11, 2016.

*Correspondence: E-mail: mzavelevych@yahoo.com Abbreviation used: MDS - myelodysplastic syndrome. as total were recorded as the single entry without subdivision into the specific forms of these diseases. Nevertheless, even in the recent edition of the National Cancer Registry of Ukraine only four categories related to hemoblastoses are delineated, namely "leukemia", "Hodgkin disease", "non-Hodgkin lymphoma", and "multiple myeloma" [4]. Several specialized cancer registries developed for the populations suffered from Chornobyl accident should also be mentioned.

In the 60s-80s, hemoblastoses were among the most prevalent malignancies in the population of Ukraine (then Ukrainian SSR). The overall agestandardized (world standard) incidence rate of hemoblastoses for male and female populations in Ukraine amounted to 9.9 and 6.3 per 100,000 in 1968-1972 and 12.4 and 7.9 per 100,000 in $1977-1981$ [5]. At that time, the hemoblastoses (in total) ranked the third in males and the fifth in females (excluding intentionally nonmelanoma skin cancer) [6]. The increasing incidence rate of hemoblastoses both in male and female populations of Ukraine in 1965-1981 was evident [6]. In 19891990, the incidence rate of hemoblastoses in Ukraine amounted to 15.9 per 100,000 for males and 10.1 per 100,000 for females. In 1971-1990, the average annual gain in the incidence rate was $2.3 \%$ for males and $2.5 \%$ for females with the maximal increment in $70+$ age group (both in males and females, respectively, 5.5\% and $4.4 \%$ annually) [5]. Quite unexpectedly, in 19911996 the incidence of hematopoietic malignancies in Ukraine dropped by $3.5 \%$ that was explained by the incomplete information provided by the network of the primary cancer care facilities in their reports to cancer registry system as well as poor standards of diagnostic routine at the local level [7]. In 1989-1990, in Ukraine the maximal hemoblastosis incidence in males was recorded in 70-74 age group (69.5 per 100,000) and in females in 65-69 age group (33.8 per 100,000). As to the death rate, in 1989-1990 in Ukraine leukemia death rate was 6.3 and 3.8 per 100,000 for males and females, respectively. The death rate for other forms 
of hemoblastoses was 5.0 and 2.7 per 100,000 (world population standard).

According to the official statistical data of 70 s of the last century, the incidence and death rates due to hemoblastoses as well as their year-by-year trends in exUSSR resembled the corresponding indices in several European countries [8]. For example, in Belarus, the average standardized incidence rate for leukemia per 100,000 amounted to 6.5 and 3.9 in males and females, respectively, in 1977-1985 and 9.0 and 5.3 in 19861994. The corresponding figures for non-Hodgkin lymphoma were 0.7 and 0.6 per 100,000 in $1977-1985$ and 1.3 and 0.9 in 1986-1994 [9]. The maximal rates were recorded in Baltic countries, Belarus, Ukraine and Armenia (then the republics of the USSR). In 1980, the incidence rates for all hematopoietic malignancies for males and females (calculated per 100,000) amounted to 17.2 and 11.6 in Belarus, 20.8 and 14.8 in Latvia, 21.7 and 16.8 in Lithuania, 14.8 and 9.1 in Ukraine. In Russian Federation, the incidence of malignancies of hematopoietic and lymphoid tissues in males was 10.8 per 100,000 in 1981 and 12.4 per 100,000 in 1993 with the annual growth increment of $3.0 \%$ in $1981-1986$ and $0.3 \%$ in $1987-1993$; in females the incidence of hematological malignancies was 7.2 per 100,000 in 1981 and 8.5 per 100,000 in 1993 with the annual growth increment of $2.0 \%$ in $1981-1986$ and $1.1 \%$ in $1987-1993$ [10]. Nevertheless, the serious underestimation due to insufficient diagnostic level is evident by the above incidence and death rates compared with those in Western countries. It should be also noted that in ex-USSR only limited isolated comparative descriptive studies were provided $[8,11]$.

The Ukrainian trends in incidence rates of hematopoietic malignancies outlined above may be compared with such trends worldwide based on the data from corresponding national registries giving an insight into the global trends within the same temporal span, namely from 1979 to 1990 . It should be noted that as early as in the 70s, the national registries of Western countries have accounted for several categories of hematopoietic malignancies rather than hematoblastoses as a whole.

As an example of the European trends, in UK the standardized incidence of leukemia (European standard) increased from 15.1 per 100,000 in males and 8.3 per 100,000 in females in 1979 to 18.1 and 10.1 per 100,000 in males and females, respectively, in 1990. The incidence of non-Hodgkin lymphoma increased from 10.1 per 100,000 in males and 6.8 per 100,000 in females in 1979 to 18.2 and 12.1 per 100,000 in males and females, respectively, in 1990. The corresponding incidence rates for multiple myeloma were 6.6 and 4.4 per 100,000 in 1979 and 8.6 and 5.8 per 100,000 in 1990 for males and females, respectively [12].

Based on population-based cancer registries in USA within the framework of the Surveillance, Epidemiology, and End Results (SEER) Program of the National Cancer Institute, age-adjusted incidence in USA per
100,000 were for leukemia 16.8 in males and 9.7 in females in 1979, 17.4 and 9.8, respectively, in 1990; for non-Hodgkin Iymphoma 14.2 and 11.2 in 1979 , 23.0 and 14.8 in 1990; and for multiple myeloma 6.0 and 4.1 in 1979, 7.3 and 4.6 in 1990 [13].

Besides the general temporal and spatial trends in leukemia incidence, several studies focused on the comparison of such indices in populations of contaminated and non-contaminated areas accounting for the incidence of hematopoietic malignancies in the regions (and even districts) in Ukraine, Belarus and Russian Federation with varying levels of contamination with radionuclides.

In Ukraine, Prysyazhnyuk et al. [14] analyzed the calculated individual average dose equivalents in the most contaminated regions and statistical data on cancer incidence in the same regions in 1980-1993. The study also included the analysis of the incidence of malignant neoplasms including leukemia and lymphomas among population in small areas of Ukraine, which suffered utmost from the contamination with radionuclides due to the Chornobyl accident, namely Narodychi, Ovruch districts of Zhytomyr region and Polissia, Ivankiv and Chornobyl districts of Kyiv region. The map-matching method was also used for the comparative analysis of territorial distribution of cancers for studying pre-Chornobyl (1980-1985) and post-Chornobyl incidence rates. Dynamic models of incidence rates of malignant neoplasms in the most contaminated territories of Zhytomyr and Kyiv regions of Ukraine before and after the Chornobyl accident were analyzed [14]. When leukemia incidence was compared in different age groups, the incidence in the older persons (> 65 years) increased since 1987 (in separate post-Chornobyl years 2-3-fold increase was registered). Nevertheless, in the persons of other age groups leukemia incidence prior to and after Chornobyl accident was quite similar. Since radiogenic excess might be attributable mainly to relatively young persons, one could not associate such increase with radiogenic factor. The trends in increment of incidence rates for hemoblastoses prior to 1986 and after 1986 were of the same direction.

When incidence rates of leukemia and lymphomas were analyzed year-by-year in contaminated regions (Kyiv and Zhytomyr), separately in the most contaminated districts of these regions, and in Ukraine as whole, the temporal annual fluctuations of incidence rates of leukemia and lymphomas in separate years were noted, especially in the most contaminated areas. Moreover, the increase in incidence rates in 19871991 was followed by the decrease in the subsequent years. The regression coefficients of the dynamic series for 1980-1997 were calculated as 0.14 for entire Ukraine, 0.19 for Kyiv region, 0.31 for Zhytomyr region, and 0.31 for most contaminated areas, although due to high standard error values the differences were not significant $[15,16]$. Moreover, taking into account that the minimum latent period of leukemia is 2 years and the peak of incidence is $6-8$ years, the observed 
transient increase could not be associated with radiation. The dynamic models for several specific subtypes of leukemia and lymphomas also were analyzed in this study [15]. Again, the increased lymphoid leukemia incidence (the type of leukemia was not specified by the authors) and myeloid leukemia observed in 1986-1991 does not suggest the radiation effects because of short latency.

Prysiazhnyuk et al. [17] pointed out that the committed individual life-time doses in the population of several districts heavily contaminated with radionuclides may amount to $70 \mathrm{mSv}$. Therefore, the thorough analysis of the stochastic effects of radiation in such specific groups of population in Ukraine is required. In particular, cancer incidence for the period 1980-2000 was analyzed in a cohort of 125,000 residents from the most contaminated districts and 51,500 persons relocated from Chornobyl area. In general, cancer rate in the populations still living in the most contaminated districts did not exceed that for the overall Ukraine or for Kyiv and Zhytomyr regions. Leukemia and lymphoma incidence rates increased in 1986-1991, 1992-1997, and 1998-2000 in comparison with the pre-accident period (1980-1985). The temporal differences in the incidence of specific forms of these diseases were also evaluated. An increase was demonstrated for lymphoid leukemia in 1986-1991, 1992-1997, 1998-2000 and myeloid leukemia in 1986-1991 and 1998-2000 (the forms were not specified by the authors) [17, 18]. In persons relocated from contaminated regions, the incidence of leukemia and lymphoma was elevated only for the 1990-1993 sub-period.

Nevertheless, the overall regression coefficients for this entire period of the study do not suggest any significant difference among contaminated vs noncontaminated territories. One should also bear in mind the large-scale migration of population from contaminated areas challenging the complete coverage of the persons exposed to radiation due to Chornobyl accident [16, 18].

Recently, Prysyazhnyuk et al. [19] have updated and summed up the analysis of the incidence rate of malignant diseases including hematological malignancies in a cohort of the residents of Ukraine inhabiting the most contaminated areas. The recent analysis covers 35 years (1976-2010) and is based on the statistical data provided by the Ministry of Health of Ukraine. The incidence of the malignant diseases of hematopoietic and lymphoid tissues increased through 1976-1990 while in 1991-2010 the increase in incidence rates slowed down significantly [19]. And again, the analysis of the dynamic series in the incidence of hematopoietic malignancies prior to 1986 and after 1986 for the inhabitants of the utmost contaminated areas demonstrated the complete similarity of these temporal trends. The increased incidence of leukemia was consistent with pre-existing ascending trends. Post-Chornobyl increase in incidence rate for leukemia and lymphoma in the most contaminated areas fits completely the increased incidence rate in Ukraine when the same periods are compared. The authors pointed out that the extensive migration of population including the possible groups at risk should be taken into account. Therefore, the monitoring of hematological malignancies should cover not only contaminated areas but also outside locations, especially at the sites of the compact residence of specific groups of the population [19].

Several other studies on the incidence of leukemia in the areas with different levels of contamination were performed in Ukraine. Lukavetsky studied the incidence and death rates of hematopoietic malignancies in the population of Rivne (as contaminated) and Ivano-Frankivsk (as non-contaminated) regions in 1981-1994 [20]. The standardized incidence rates of hematoblastoses increased when the periods of 1981-1985 and 1987-1994 were compared. Such increase was attributed mainly to the increase in the incidence rate of chronic lymphocytic leukemia and non-Hodgkin lymphoma as well as myeloma in aged patients. Nevertheless, the death rate due to leukemia and lymphoma was similar in contaminated and non-contaminated districts. Leukemia and lymphoma morbidity and mortality rate increased mainly during the period of 1987-1994 in both regions, irrespectively of their contamination with radionuclides. The increase was most pronounced in older age groups of the population of both regions. It is of importance that no trends in incidence rate for hematological malignancies have been identified in younger populations of these two regions [20].

Another paper in this series focused on the analysis of hemoblastosis incidence and the structure of leukemia in Rivne region with six districts contaminated with radionuclides. The increased incidence of hematological malignancies for 11 post-Chornobyl years was ascertained as compared to the years preceding Chornobyl catastrophe. Among the specific types of hematological malignancies, the incidence of acute leukemia, multiple myeloma and malignant lymphoma increased significantly. Nevertheless, the difference in incidence rate in contaminated and noncontaminated regions of Rivne region was not evident; neither the association of the incidence rate with the effective equivalent dose was observed [21].

Within the framework of the French-German Initiative, the multinational health project was implemented from 1997 through 2004 in Belarus, Russian Federation and Ukraine. Leukemia incidence was studied either at the national level or in several regions by comparing contaminated with only slightly contaminated regions [22]. In Ukraine, the slight augmentation in the incidence rate of leukemia in Zhytomyr and Kyiv regions was registered compared with the period before the Chornobyl accident although the differences with the all-Ukrainian rate are quite small. A comparative analysis of the particular types of leukemia demonstrated that incidence rates of acute lymphoblastic and acute myeloid leukemia in 1987-1992 and 1993-1999 are 
moderately higher than in 1980-1986. Where the data of Chernihiv region contaminated with radionuclides were compared with those of the relatively clear Sumy region, leukemia incidence rates fluctuated between these zones before and after the accident. But the incidence observed in the contaminated region has never exceeded the national mean. It should be also noted that in the contaminated region, the incidence rates for men older than 44 years were higher after the accident than before.

The conclusions of the study within framework of the French-German Initiative confirming the absence of the excess of leukemia in the inhabitants of the contaminated territories of Ukraine were outlined in the National Report of Ukraine "20 Years of Chornobyl catastrophe" [23].

The data on leukemia incidence in 2001, 2006 and 2012 for the population of six regions of Ukraine heavily contaminated with radionuclides, Kyiv city and Ukraine in whole calculated in National Cancer Registry of Ukraine [4] are given in Table.

Table. Leukemia incidence in population of six regions of Ukraine heavily contaminated with radionuclides in 2001, 2006, and 2012

\begin{tabular}{lcccccc}
\hline \multirow{2}{*}{ Region } & \multicolumn{2}{c}{2001} & \multicolumn{2}{c}{2006} & \multicolumn{2}{c}{2012} \\
\cline { 2 - 7 } & Males & Females & Males & Females & Males & Females \\
\hline Vinnytsia & 6.8 & 4.4 & 8.3 & 6.8 & 9.8 & 7.3 \\
Volyn & 9.8 & 6.3 & 7.5 & 3.8 & 8.6 & 5.6 \\
Zhytomyr & 7.2 & 5.6 & 9.8 & 4.8 & 7.8 & 5.9 \\
Kyiv & 6.4 & 5.1 & 6.9 & 5.8 & 7.9 & 4.9 \\
Rivne & 8.4 & 6.8 & 5.1 & 5.1 & 8.7 & 5.5 \\
Chernihiv & 6.8 & 5.1 & 9.0 & 4.7 & 7.6 & 5.3 \\
Kyiv city & 6.3 & 5.6 & 8.5 & 6.0 & 8.3 & 5.8 \\
Ukraine in whole & 7.8 & 5.0 & 7.5 & 4.7 & 7.9 & 5.4 \\
\hline
\end{tabular}

Note: The data are given according to statistics compiled by the National Cancer Registry of Ukraine [4]. The standardized incidence rates (world standard) per 100,000 males and females are provided. The data for the population of Kyiv city as well as Ukraine as whole are also given for comparison.

The data in the Table demonstrate that actually the increased incidence rate throughout 2001-2012 was evident only in Vinnytsia region (for both males and females) and Kyiv city (for males only). In Zhytomyr and Chernihiv regions, the leukemia incidence in males increased through 2001-2006 followed by the decrease through 2006-2012. In Ukraine as whole, the leukemia incidence in 2001-2012 was practically at the same level both in males and females.

It is of interest to mention that according to the data of the National Cancer Registry of Ukraine the highest registered incidence rates of leukemia were in Crimea and Sevastopol ( 11.3 per 100,000 in males and 6.7 per 100,000 in females in 2001 in Crimea and 10.8 per 100,000 in males and 7.4 per 100,000 in females in Sevastopol in 2001). Therefore, some other factors of leukemogenesis should be taken into account such as excess insolation [24] or otherwise it is a problem of different diagnostic efficacy or consistency in accounting the patients in different regions. By the way, the latter may well be the reason of the increased leukemia incidence rate in Vinnytsia region throughout 12-year interval being analyzed.

The analysis of the dynamics in leukemia incidence rates in the population of six regions of Ukraine that are most contaminated with radionuclides is in line with the findings of the above-mentioned studies. Overall, the changes of the incidence levels seem to be connected with overall temporal trends and not with the levels of contamination.

It should also be noted that the most studies of leukemia risks in the territories stated above are rather ecological in their design and should be followed by the analytical epidemiologic approaches. In general, such studies demonstrate that the incidence rate of various types of hematological malignancies increased with time that coincides with general temporal trends both in the contaminated and non-contaminated regions but do not point out association with the level of contamination with radionuclides [18]. Due to this reason, the results of studies in residents of contaminated with radionuclides territories concerning leukemia risk remain unconvincing.

In Russian Federation the extensive study was performed on cancer incidence and death rate in Bryansk, Kaluga, Orel, and Ryazan regions, which are known as the most radiocontaminated after the Chornobyl accident [25]. The study comprised the dynamics of morbidity indices in 1981-1994 and the assessment of relative risks of malignant neoplasms, leukemia in particular, among population of the most contaminated regions as compared to Russian Federation in whole before and after the Chornobyl accident. The standardized incidence of malignancies of hematopoietic and lymphoid tissues per 100,000 was compared in 1979 and 1993. It was demonstrated that incidence rate both in males and females in Bryansk, Tula, Ryazan regions is somehow higher than in Russian Federation in whole both in preChornobyl and post-Chornobyl period. In Bryansk region, the incidence in 1979 and 1993 was 11.1 and 13.1 per 100,000 in males and 7.0 and 11.7 per 100,000 in females. In Kaluga region, the corresponding figures were 8.3 and 12.5 in males (with increase up to 16.1 in 1991) and 4.2 and 9.1 in females. In Orel region -11.5 and 10.3 in males and 5.9-6.9 in females (with increase up to 10.7 in 1988). In Tula region 9.9 and 14.8 in males and 6.5 and 10.6 in females. In Ryazan region -11.9 and 13.1 in males (with increase up to 16.5 in 1990) and 11.1 and 13.1 in females. Meanwhile, when the incidence of leukemia in 1993 was studied in the districts grouped in all these regions by their contamination levels, the indices were rather similar [25].

In another study, the morbidity of leukemia and other hemoblastoses in 6 south-west districts of Bryansk region (territory of observation), the remaining 21 districts (territory of comparison), and Bryansk city was compared [26]. Data in contaminated districts of Bryansk region in 1986-1993 suggest the excess of acute lymphoblastic leukemia only in children, not adults. However, very short latency in several cases makes questionable the causative relationship. In the following 7 years, the relative risk of all forms of leukemia in population of the most contaminated areas was not more than 1.0 both for children and for adults [26]. Analysis 
of dynamic trends of leukemia incidence demonstrated the statistically significant gain in the incidence of acute leukemia and lymphomas in post-Chornobyl period. Nevertheless, the standardized incidence for all hematopoietic malignances was similar in highly contaminated districts and relatively non-contaminated districts of Bryansk region ( 15.85 vs 15.50 per 100,000 males and 10.59 vs 14.23 per 100,000 females standardized according to population of the same Bryansk region). The increase in relative risk was not found out except for Bryansk city where the standardized incidence rate was higher (22.15 per 100,000 males and 19.97 per 100,000 females) and the relative risk for most hemoblastoses exceeds 1.0. While in the most contaminated territories the chronic forms of leukemia contributed to the slight increase in the incidence of hematological malignancies such differences were not statistically significant. Moreover, in this region in the post-accidental period a positive trend of increased incidence of acute leukemia and non-Hodgkin lymphomas was detected. Nevertheless, the authors do not believe that the differences that were revealed are sufficient for suggesting the causal relationship between risk of leukemia and radiation effect due to the Chornobyl accident.

Overall, the analysis of the long-term medical consequences of Chornobyl accident for the persons inhabiting the contaminated areas of Russian Federation as well as for the persons relocated from the highly contaminated areas did not reveal the excess of leukemia incidence rates over the spontaneous levels [27].

The National Report of Russian Federation "20 Years of Chernobyl catastrophe" [28] summarized the conclusions of the above papers confirming the absence of excess in leukemia incidence in adult population of the most contaminated areas including those who were evacuated.

The same was stated within the framework of the French-German Initiative [22]. Namely, in Russian Federation no excess leukemia incidence between 1986 and 1998 in the highly contaminated districts of Bryansk region compared with the general Russian population was observed. The comparison of leukemia incidence rates in the highly contaminated Bryansk region and Kaluga region analyzed as relatively noncontaminated one did not demonstrate significant differences in all types of leukemia.

In Belarus, starting from 1992, a significantly increased incidence of all forms of leukemia was identified in the adult population. The greatest increase was observed during 1992-1994 as compared to the pre-Chornobyl period [29].

In one study focusing on Chornobyl problems, the standardized incidence rates of hemoblastoses were compared prior to Chornobyl accident (19791985 ) and in two periods after Chornobyl accident (1986-1992 and 1993-1997) [30]. The incidence of acute leukemia was shown to increase in the first post-Chornobyl period ( 3.17 per 100,000 vs 2.82 per 100,000 before 1986). The same dynamics was revealed for chronic lymphocytic leukemia (8.14 per
100,000 vs 6.09 per 100,000 before 1986). The increase was shown to be statistically significant [30]. Also, the increased incidence rate was demonstrated for multiple myeloma, Hodgkin Iymphoma and non-Hodgkin lymphomas. For several forms of hematological malignancies the increased incidence rate continued to persist through the second (late) post-Chornobyl period (1993-1997). In the second post-Chornobyl period the increased rate of myelodysplastic syndromes (MDS) was also evident. The significant increase in leukemia incidence among the aged persons was also found out.

The National Report of Belarus "20 Years of Chernobyl catastrophe" stated the increase in leukemia incidence, in particular multiple myeloma and nonHodgkin lymphomas in adult population in Gomel and Mogilev regions (both contaminated and noncontaminated areas) in 1979-1985 as compared to $1993-2003$ [31].

The studies on leukemia incidence in Belarus were summarized also within the framework of the French-German Initiative [22]. It was stated that the overall national standardized incidence rate of acute leukemia as well as chronic lymphocytic leukemia and chronic myeloid leukemia in 1986-1992 was slightly higher than in the pre-accident period (19791985). In 1993-1997, the incidence rate of leukemia was slightly declined. Of particular note is the increase in polycythemia vera rate from 0.56 per 100,000 in $1979-1985$ to 0.85 in 1993-1997. Nevertheless, in the most contaminated regions of Belarus (Mogilev, Gomel and Brest regions), the time trends for the polycythemia vera incidence rate were the same as in other regions. The standardized rates of different types of leukemia for each study period remained similar to those of Vitebsk region considered as noncontaminated one [32].

The leukemia incidence and patterns of specific forms in the structure of hematological malignancies in the persons evacuated from the contaminated regions did not differ from that in Belarus in whole. Importantly, the emerging trend of increasing incidence of MDS became evident in the adult population of Belarus since 1996. In particular, in Mogilev, Gomel and Brest regions 1.5-2.0-fold increase in MDS incidence was registered. In Mogilev region, MDS incidence increased up to 3.0 per 100,000 in 1997 as compared to 0.9 per 100,000 in Belarus as whole [33].

The actual epidemiological data were used for assessing the probable excess of leukemia cases in population exposed to low-dose radiation due to Chornobyl catastrophe for life-time of Chornobylaffected generation. However, such risk projections according to various sources differ substantially taking into account the inherent uncertainties in the estimates of the effects of Chornobyl accident.

In particular, Cardis et al. [34] calculated the predicted number of fatal cancers and leukemia in the population of the most contaminated areas based on risk estimates derived from studies of survivors 
of the atomic bombing allowing for the modifying effects of age at exposure and sex. According to calculations, 100 excess leukemia deaths are expected for life-time in 270,000 residents of strict control zone ( $9 \%$ of life-time deaths in this group will be attributable to radiation). Moreover, 370 excess leukemia deaths are predicted for life-time in $6,800,000$ residents of other contaminated areas (1.5\% of life-time deaths in this group will be attributable to radiation). It should be noted that the fraction of excess leukemia cases is much higher for the first 10 years. In principle, such increases would be very difficult to detect epidemiologically and the predictions suffer much from uncertainty. In addition, the extrapolation of the effects of A-bomb exposure to lower dose and lower dose rate protracted exposures after Chornobyl is subject to uncertainties since evidence from other studies (such as workers in the nuclear industry) suggests that low dose protracted exposures to ionizing radiation may increase the relative risk of cancer.

Based on the real numbers of radiogenic cancers recorded for 1986-2000 in the contaminated territories of Belarus and Ukraine, Malko [35] calculated the ratio between radiation dose and the number of additional cancers attributable to that dose by comparing pre-Chornobyl and post-Chornobyl number of cancer patients and transferring the radiation risks established for the Belarusian population to other affected populations. Based on the current data of the official Belarusian health statistics and his estimates of radiation exposure in various regions of Belarus, Malko estimated that the Chornobyl accident could result in an additional 2800 extra cases of leukemia in Belarus between 1986 and 2056, with up to 1880 of these being fatal. In Ukraine for the same period 2801 excess leukemia with 1989 fatalities are calculated and in Russian Federation -2512 and 1784 , respectively.

Overall, the results of epidemiological studies in Ukraine, Belarus and Russian Federation do not suggest the radiation-associated excess of leukemia in population of the utmost contaminated areas of these countries. Nevertheless, one has to agree with the opinion that such epidemiological studies should be continued, especially with the involvement of the analytical epidemiology methods that were not in wide use as applied to the analysis of oncohematological consequences of Chornobyl accident among the adult population evacuated from Chornobyl area and those still inhabiting the contaminated districts.

Studying leukemia incidence in bulk without delineating the separate biological forms of leukemia may disguise the radiation effects on induction of specific forms of hematological diseases taking into account the different association of specific forms of leukemia and lymphoma with ionizing radiation. Cardis et al. [34] pointed out that analytical epidemiological studies focusing on specific diseases and populations may be a more useful approach to investigating the effects of radiation exposure among the exposed populations.
In fact, the results of the analysis in which the forms of leukemia known or suspected as associated with radiation exposure are treated separately may be quite different from those based on bulk data. Therefore, the comparison of the incidence patterns of distinct biological forms of leukemia in contaminated and non-contaminated regions of Ukraine remains a topical issue [36].

Another promising approach consists in studying leukemia incidence in the separate categories of the exposed populations considered as most vulnerable to the stochastic effects of the ionizing radiation. Among them are those exposed to radiation in 1986-1987 in childhood or in utero. One such casecontrol study was in fact performed in Ukraine [37]. Noshchenko et al. analyzed leukemia cases that occurred in 1987-1997 among the residents of the most contaminated regions of the Ukraine, namely Zhytomyr and Rivne, who were aged $0-20$ at the time of Chornobyl accident. A statistically significant association of the risk of acute lymphoblastic and acute myeloid leukemia among subjects aged $0-20$ at the time of the accident was found with radiation exposure $>10 \mathrm{mSv}$, particularly in males [37].

In two recent studies in Ukraine and Belarus [38, 39], the incidence of leukemia and lymphoma were analyzed in the cohorts of persons who were under the age of 18 years in 1986 and who had direct measurements of thyroid radioactivity shortly after the accident. The main attained age at the moment of the study was above 30 years. Neither of these studies has registered increased incidence of leukemia and lymphoma. Nevertheless, the authors consider it important to continue monitoring the cohorts exposed at sensitive ages.

Evaluation of health status of the population affected by the Chornobyl accident remains one of the most important problems in the correct assessment of the oncological consequences of the disaster. The analysis of the trends in leukemia incidence and death rates requires the reliable and comprehensive system of recording the disease cases and follow-up of leukemia patients, which may be operative only on the basis of the precise diagnosis and sufficient coverage. The proper use of the current International Classifications of Hematopoietic Malignancies (2008 WHO Classification of Tumors of Hematopoietic and Lymphoid Tissues and its 2016 revision) is also challenging for healthcare network as well as research facilities in Ukraine, Belarus and Russian Federation. It should be mentioned that the data on leukemia incidence in Ukraine are underestimated due to several reasons. Several forms of hematopoietic malignancies (MDS and several forms of myeloproliferative neoplasms) are not reported in the National Registry. It is evident that only verified diagnosis could generate the strong basis for the advanced studies in analytical epidemiology of leukemia aimed at elucidating the role of the radiogenic factor in the pathogenesis of hematological malignancies. In this context, the improvement of the 
general standards of diagnosing malignancies of hematopoietic and lymphoid tissues at the local level and the verification of the diagnosis by reference laboratories is a problem of high priority.

\section{REFERENCES}

1. Preston DL, Kusumi MA, Izumi S, et al. Cancer incidence in atomic bomb survivors. Part III. Leukemia, lymphoma and multiple myeloma, 1950-1987. Radiat Res 1994; 137: S68-S97.

2. Cardis E, Anspaugh L, Ivanov VK, et al. Estimated long term health effects of the Chernobyl accident. In: One Decade after Chernobyl. Summing up the Consequences of the Accident. Proceedings of an International Conference, Vienna, 1996. STI/PUB/1001. IAEA, Vienna, 1996: 241-79.

3. Ivanov VK, Tsyb AF, Gorsky AI, et al. Leukaemia and thyroid cancer in emergency workers of the Chernobyl accident: estimation of radiation risks (1986-1995). Radiat Environ Biophys 1997; 36: 9-16.

4. National Cancer Registry of Ukraine [homepage on the Internet]. Kyiv: National Cancer Registry of Ukraine [cited 2016 November 29]. Available from: http://www.ncru.inf.ua/publications/index.htm.

5. Guslitser LN, Gluzman DF, Abramenko IV. Comparative analysis of the modern international statistical and morphological classifications of the malignancies of lymphoid and hematopoietic tissue. Oncology 1999; (1): 51-4 (in Russian).

6. Guslitser LN. Epidemiology of Malignant Tumors in Ukraine. Kyiv: Naukova Dumka, 1988. 184 p. (in Russian).

7. Fedorenko ZP, Mishchenko AN, Hulag LO, et al. Prevalence of malignancies in population of Ukraine in 19911996 (epidemiological and organizational aspects of the problem). Kyiv: Ministry of Health of Ukraine, Ukrainian Research Institute of Oncology and Radiology, 1997. 116 p. (in Ukrainian).

8. Khokhlova MP. Epidemiological study of leukemia and lymphoma. In: Cancer Epidemiology in USSR and USA. Blokhin NN, Sneiderman MA, eds. (Joint USSR-USA edition). Moscow: Meditsina, 1979: 357-67 (in Russian).

9. Okeanov AE, Yakimovich GV, Vanagel SA. Cancer incidence tendencies change in post Chernobyl period in the Republic of Belarus. Radiat Risk 1995; (6): 216-35 (in Russian).

10. Ivanov VK, Remennik LV, Tsyb AF. Radiation oncoepidemiology in Russia after the Chernobyl accident: prognostication and facts. Radiat Risk 1995; (6): 26-77 (in Russian).

11. Martirosov AR, Osechinskii IV. Incidence of leukemia and other hemoblastoses. Klin Med (Mosk) 1975; 53 (4): 19_ 25 (in Russian).

12. Cancer Research UK [homepage on the Internet]. Cancer Research UK [cited 2016 November 29]. Available from: http://www.cancerresearchuk.org/.

13. Surveillance, Epidemiology and End Results Program [homepage on the Internet]. NCI's Division of Cancer Control and Population Sciences [cited 2016 November 29]. Available from: http://seer.cancer.gov/csr/1975_2013/.

14. Prysyazhnyuk AYe, Gristchenko VG, Zakordonets VA, et al. Study of possible radiation cancers upon the Chernobyl NPP accident in the territories of Ukraine most severely contaminated with radionuclides. Radiat Risk 1996; (6): 20115 (in Russian).

15. Prysyazhnyuk AYe, Gulak LO, Grishtshenko VG, Fedorenko ZP. Cancer incidence in Ukraine after Chernobyl accident. In: Chernobyl: Message for the 21st Century. Proceedings of the Sixth Chernobyl Sasakawa Medical Cooperation Symposium held in Moscow, Russia May 30-31, 2001. International Congress Series 1234, Amsterdam: Elsevier, 2002: 281-91.
16. Prysyazhnyuk AYe, Grystchenko VG, Fedorenko ZP, et al. Epidemiological study of cancer in population affected after the Chernobyl accident. Results, problems and perspectives. Int J Radiat Med 1999; (2): 42-50.

17. Prysyazhnyuk AY, Fedorenko ZP, Gulak LO, Fusik MM. Review of epidemiological finding in study of medical consequences of the Chernobyl accident in Ukrainian population. In: Research Activities about the Chernobyl NPS in Belarus, Ukraine and Russia. Imanaka T, ed. Kyoto University Research Reactor Institute (KURRI-KR-79), Kyoto, 2002: 190-203.

18. Prisyazhniuk A, Grishchenko V, Zakordonets V, et al. The time trends of cancer incidence in the most contaminated regions of the Ukraine before and after the Chernobyl accident. Radiat Environ Biophys 1995; 34: 3-6.

19. Prysyazhnyuk AYe, Bazyka DA, Romanenko AYu, et al. Risk of malignant tumors in groups of population affected by the Chornobyl accident. Environ Health 2013; (3): 34-41 (in Ukrainian).

20. Lukavetsky LM. Leukemias and lymphomas morbidity in contaminated and uncontaminated by radionucleades areas caused by Chornobyl catastrophe. Thesis for a candidate's degree of medical sciences. Kyiv: Research Institute of Hematology and Blood Transfusion, 1999. 19 p. (in Ukrainian).

21. Vygovskaia YaI, Kachorovskyi BV, Mazurok AA, et al. Hemoblastosis morbidity in Rivne region of Ukraine prior to and after Chernobyl NPP accident. Hematol Transfusiol 1994; 39 (3): 22-4 (in Russian).

22. French-German initiative for Chernobyl Health Project Report DRPH/2006-10 [report on the Internet]. Institut de Radioprotection et de Sûreté Nucleare; German nuclear plant and reactor safety authorities [cited 2016 November 29]. Available from: http://www.irsn.fr/EN/Research/ publications-documentation/Publications/ DRPH/SER/ Documents/ RAPPORT_IFA-FGI-2006_VA.pdf.

23. 20 Years of Chernobyl Catastrophe. Future Outlook. National Report of Ukraine. Kyiv: Atika 2006. 232 p. (in Ukrainian).

24. Guslitser LN, Khaetsky IK. Radiation and cancer. Synergism of carcinogenic effects of ionizing and UV radiation (epidemiological and prophylactic aspects). In: Anthropogenically Changed Environment of Ukraine: Health Risks for Population and Risks for Ecological Systems. Ekolohichnyi Visn (Special Issue). Kyiv: Chornobylinterinform 2003: 319-26 (in Ukrainian).

25. Ivanov VK, Remennik LV, Tsyb AF. Radiation oncoepidemiology in Russia after the Chernobyl accident: prognostication and facts. Radiat Risk 1995; (6): 26-77 (in Russian).

26. Osechinsky IV, Martirosov AR, Zingerman BV, et al. Leukemia and other hemoblastoses in Bryansk oblast of Russia after the Chernobyl accident. Radiat Risk 1995; (6): 184-200 (in Russian).

27. Ivanov VK, Tsyb AF. Medical Radiological Consequences of Chernobyl for Population of Russia: Estimation of Radiation Risks. Moscow, 2000. 392 p. (in Russian).

28. 20 Years of Chernobyl Catastrophe. Outcomes and Problems for Overcoming the Consequences in Russia 19862006. Russian National Report of the Ministry of RF on Civil Defense, Emergency Situation and Recovery from Natural Disasters. Moscow: Ministry of Health and Social Development of Russian Federation, 2006. 92 p. (in Russian).

29. The Chernobyl Catastrophe Consequences on Human Health. In: Yablokov A, Labunska I, Blokov I, eds. Amsterdam: Greenpeace International, 2006. 184 p.

30. Gapanovych VN, Shuvaieva LP, Yaroshevich RF, et al. Incidence of hemopathies in adults of Republic Belarus in 1979-1997. In: $3^{\text {rd }}$ International Conference "Medical 
consequences of Chernobyl catastrophe: Results of 15-years studies". June 4-8, 2001. Kyiv 2001: 176 (in Russian).

31. 20 Years after Chernobyl Catastrophe: Consequences in Belarus Republic and Remedial Actions. National Report. Committee on consequences of Chernobyl catastrophe of the Council of Ministers of Belarus Republic. (Shevchuk BE, Gurachevskii VL, eds). Minsk, 2006. 112 p. (in Russian).

32. Cheshik AA, Vejalkin IV, Nadyrov EA. Risk of development of blood malignancies in various categories of population suffered from catastrophe in Chernobyl NPP. Probl Health Ecol 2015; (2): 78-81 (in Russian).

33. Chernobyl Accident: Consequences and Remedial Actions. National Report, $2^{\text {nd }}$ Ed. Konoplia EF, Rolevich IV, eds. Minsk: Ministry of Emergency Situation, National Academy of Sciences of Belarus, 1998. 121 p. (in Russian).

34. Cardis E, Anspaugh L, Ivanov VK, et al. Estimated long term health effects of the Chernobyl accident. In: One Decade after Chernobyl. Summing up the Consequences of the Accident. Proceedings of an International Conference Vienna, 8-12 April 1996, IAEA, 1996: 241-72.
35. Malko IV. Assessment of Chernobyl meducal consequences accident. In: The Health Effects of the Human Victims of the Chernobyl Catastrophe. Blokov I, et al., eds. Amsterdam: Greenpeace International, 2007: 194-235.

36. Rodionova NK, Koval SV, Gluzman DF, et al. On the study of hemoblastoses structure in inhabitants of regions of Ukraine with various levels of radionuclide contamination. In: Ionizing Radiation and Oncohematological Diseases. Chekhun VF, Gluzman DF, eds. Kyiv: DIA, 2016: 230-50 (in Russian).

37. Noshchenko AG, Zamostyan PV, Bondar OY, Drozdova VD. Radiation-induced leukemia risk among those aged 0-20 at the time of the Chernobyl accident: a case-control study in the Ukraine. Int J Cancer 2002; 99: 609-18.

38. Ostroumova E, Hatch M, Brenner A, et al. Nonthyroid cancer incidence in Belarusian residents exposed to Chernobyl fallout in childhood and adolescence: Standardized incidence ratio analysis, 1997-2011. Environ Res 2016; 147: 44-9.

39. Hatch M, Ostroumova E, Brenner A, et al. Nonthyroid cancer in Northern Ukraine in the post-Chernobyl period: Short report. Cancer Epidemiol 2015; 39: 279-83. 